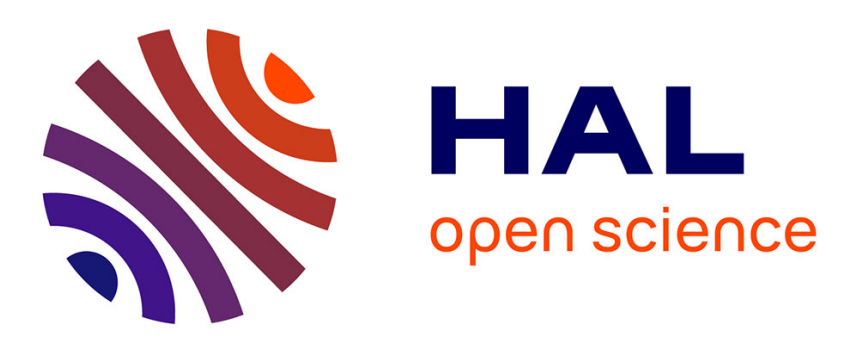

\title{
On the lithiation reaction of niobium oxide: structural and electronic properties of $\mathrm{Li} 1.714 \mathrm{Nb} 2 \mathrm{O} 5$
}

Michele Catti, Mohammad R. Ghaani

\section{To cite this version:}

Michele Catti, Mohammad R. Ghaani. On the lithiation reaction of niobium oxide: structural and electronic properties of Li $1.714 \mathrm{Nb} 2 \mathrm{O}$ 5. Physical Chemistry Chemical Physics, 2014, 16 (4), pp.1385-1392. 10.1039/C3CP54215G . hal-01541195

\section{HAL Id: hal-01541195 \\ https://hal.science/hal-01541195}

Submitted on 18 Jun 2017

HAL is a multi-disciplinary open access archive for the deposit and dissemination of scientific research documents, whether they are published or not. The documents may come from teaching and research institutions in France or abroad, or from public or private research centers.
L'archive ouverte pluridisciplinaire HAL, est destinée au dépôt et à la diffusion de documents scientifiques de niveau recherche, publiés ou non, émanant des établissements d'enseignement et de recherche français ou étrangers, des laboratoires publics ou privés. 
On the lithiation reaction of niobium oxide: structural and electronic properties of $\mathrm{Li}_{1.714} \mathrm{Nb}_{2} \mathrm{O}_{5}$

\author{
Michele Catti* and Mohammad R. Ghaani \\ Dipartimento di Scienza dei Materiali, Università di Milano Bicocca, via Cozzi 55, 20125 Milano, \\ Italy
}




\begin{abstract}
Monoclinic $\alpha-\mathrm{Nb}_{2} \mathrm{O}_{5}$ was chemically lithiated by reaction with $\mathrm{n}$-butyllithium, mimicing the product of electrochemical discharge of a niobium oxide cathode vs. a Li anode. The compound was investigated by neutron powder diffraction (D2B equipment at ILL, France) and its structure was Rietveld refined in space group $P 2$ to $w R_{p}=0.045$, locating the Li atoms inserted in the $\alpha-\mathrm{Nb}_{2} \mathrm{O}_{5}$ framework. The ensuing chemical formula is $\mathrm{Li}_{12 / 7} \mathrm{Nb}_{2} \mathrm{O}_{5}$. A part of $\mathrm{Li}$ atoms are more strongly bonded (five coordinated $\mathrm{O}$ atoms), a part are less (coordination number $=4$ ). Starting from the experimental structure, first-principles periodic calculations based on the hybrid B3LYP functional were performed. The electrochemical voltage of $\mathrm{Li}$ insertion was computed to be $1.67 \mathrm{~V}$, fully consistent with the experimental $1.60 \mathrm{~V}$ plateau vs. capacity. An analysis of the electron band structure shows that lithiation changes the insulating oxide into a semi-metal; some of the extra electrons inserted with lithium become spin-polarized and give the material weak ferromagnetic properties.
\end{abstract}




\section{Introduction}

In the research field on rechargeable lithium batteries, an important role is played by the search for electrode materials with a medium to low discharge voltage vs. $\mathrm{a} \mathrm{Li}^{+} / \mathrm{Li}$ anode (2.5 to $1.0 \mathrm{~V}$ range). This contrasts with the well known trend towards higher and higher cathode voltages, aiming to attain the maximum energy density (cf. the $4.8 \mathrm{~V}$ of the $\mathrm{LiNi}_{0.5} \mathrm{Mn}_{1.5} \mathrm{O}_{4}$ cathode ${ }^{1}$ ), but it is motivated by two specific reasons. The first one concerns the use as anode rather than cathode, replacing the conventional $\mathrm{LiC}_{6}$ anode vs. a high voltage cathode like the one just mentioned above. ${ }^{2-5}$ Indeed, the electrochemical potential of conventional organic liquid-carbonate electrolytes $(1.0 \mathrm{~V})$ is slightly larger than that of the lithium or lithium/carbon anode, so that the carbonate would be reduced if no layer of passivating solid-electrolyte interface were formed, preventing the direct electrolyte-anode reaction. However, lithium dendrites tend to grow on that layer, leading to danger of short-circuits which may fire the flammable electrolyte. ${ }^{6,7}$ For this reason anodes with no passivating layer and with potentials in the 1.0 to $1.5 \mathrm{~V}$ range, so as to be exempt from possible interactions with the electrolyte, would be highly desirable. ${ }^{2-5}$ An already reported stable anode of this kind is $\mathrm{Li}_{4} \mathrm{Ti}_{5} \mathrm{O}_{12}$, with spinel structure, and working at a $1.5 \mathrm{~V}$ voltage on the basis of the $\mathrm{Ti}^{4+} / \mathrm{Ti}^{3+}$ redox couple..$^{8,9}$

The second application ( 1.5 to $2.5 \mathrm{~V}$ range) is for cathode use in batteries powering the memory backup in portable electronic devices. ${ }^{10,11}$ The microfabrication of integrated circuits brings about a reduction of power supply voltage to about $2 \mathrm{~V}$ or less, and the mismatch with a high voltage battery should be possibly avoided. That can be achieved by employing a battery cathode with electrochemical potential in the required range. With this purpose the lithium insertion reaction into $\mathrm{Nb}_{2} \mathrm{O}_{5}$ was studied electrochemically, in order to exploit the convenient potential of the $\mathrm{Nb}^{5+} / \mathrm{Nb}^{4+}$ couple. ${ }^{10,11}$ All three main polymorphs of niobium oxide were tested, finding a maximum capacity of $200 \mathrm{mAh}$ (g-oxide) ${ }^{-1}$ (i.e. $1.98 \mathrm{Li}$ atoms inserted on discharge) in the voltage range 2.2 to $1.5 \mathrm{~V}$ vs. Li anode. The behaviour of the monoclinic phase is claimed to differ slightly from that of the other modifications, because a flat portion of the potential vs. capacity curve would suggest a possible two-phase character of the reaction. However, the in-situ X-ray diffraction results are not exhaustive in this respect. Significant improvements of cycling stability and high rate capability were reported on using $\mathrm{Nb}_{2} \mathrm{O}_{5}$ nanobelts as electrode material. ${ }^{12}$

We have thus undertaken a research programme to clarify the structural and electronic properties of lithiated niobium oxides, with a particular focus on the high-temperature monoclinic phase often reported in the literature as $\alpha-\mathrm{Nb}_{2} \mathrm{O}_{5}$ or $\mathrm{H}-\mathrm{Nb}_{2} \mathrm{O}_{5},{ }^{13,14}$ the latter notation may cause possible confusion with another polymorph with hexagonal symmetry. In order to solve the 
challenging structural problem (14 f.u. are contained in the unit-cell of $\alpha-\mathrm{Nb}_{2} \mathrm{O}_{5}$ ), ${ }^{15}$ an accurate neutron diffraction study of the lithiated oxide is necessary; we thus decided to perform the lithium insertion reaction chemically to obtain a sample in the required form and amount. By locating the lithium atoms in the niobium oxide framework an important insight into the mechanism of the insertion reaction was expected; further, this would provide the prerequisite knowledge for the subsequent theoretical analysis of the electronic and magnetic properties of the material.

In the second part of the work a detailed first-principles study of the band structure of lithiated niobium oxide is presented, using a hybrid DFT (Density-Functional-Theory)-HF (Hartree-Fock) functional which performs very well for simulating the band gap region and Fermi energy surrounding. ${ }^{16}$ The aim of this section is to provide a full understanding of how the extra electrons added to niobium oxide by the insertion of $\mathrm{Li}$ atoms modify its electronic properties from insulating to conducting ones, with possible emergence of magnetic behaviour. Several quantum-mechanical studies of lithiated compounds have shown that the theoretical approach is extremely enlightening and useful for a deep comprehension of the reversible electrode functionality in lithium batteries. ${ }^{17-}$

\section{Experimental}

Monoclinic niobium oxide was prepared by thermal annealing of commercial (Sigma-Aldrich) orthorhombic $\mathrm{Nb}_{2} \mathrm{O}_{5}$ at $1200{ }^{\circ} \mathrm{C}$ for $24 \mathrm{~h},{ }^{10}$ followed by quenching in liquid nitrogen. The product was confirmed to be pure $\alpha-\mathrm{Nb}_{2} \mathrm{O}_{5}$ by X-ray powder diffraction (Bruker D8 Advance diffractometer, $\mathrm{CuK} \alpha$ radiation). Lithiation experiments were carried out by making this compound react with n-butyllithium in hexane, under $\mathrm{N}_{2}$ flow. The reaction at $50{ }^{\circ} \mathrm{C}$ for $60 \mathrm{~h}$ produced a black powder, which was filtered, washed repeatedly with hexane and dried in a glove-box with recirculated Ar atmosphere. By X-ray diffractometry (with a protected sample holder) a single-phase pattern was obtained which could be indexed according to the monoclinic unit-cell $a=20.800$, $b=4.134, c=19.116 \AA, \beta=119.54^{\circ}$, similar to that reported previously for $\mathrm{Li}_{1.9} \mathrm{Nb}_{2} \mathrm{O}_{5}{ }^{21}$ Chemical analysis by atomic emission flame photometry gave a $\mathrm{Li}$ content of $1.8 \mathrm{Li}$ per f.u., but the $\mathrm{Li}_{1.714} \mathrm{Nb}_{2} \mathrm{O}_{5}$ chemical formula was retained because consistent with the results of the structure determination by neutron diffraction (cf. the corresponding section below).

A sample of $3 \mathrm{~g}$ of $\mathrm{Li}_{1.714} \mathrm{Nb}_{2} \mathrm{O}_{5}$ was loaded into a vanadium can which was sealed with indium wire in Ar atmosphere. Data were collected in the $5-160^{\circ} 2 \theta$ range on the high-resolution $(\Delta d / d=$ $5 \times 10^{-4}$ ) D2B powder diffractometer at the neutron source (nuclear reactor) of the Institut-Laue- 
Langevin (Grenoble, France). A primary beam monochromator of $28 \mathrm{Ge}(115)$ crystals, set at $\lambda=$ $1.595 \AA$, was employed.

All calculations for determining and analysing the crystal structure were carried out by the GSAS computer package. ${ }^{22}$ The intensity background was modeled by six Chebyshev polynomials, and the peak shape was represented by a pseudo-Voigt function (linear combination of Gaussian and Lorentzian components, with $\sigma$ and $\gamma$ half-widths, respectively). The $\sigma$ and $\gamma$ parameters vary with $\theta$ as $\sigma=\left(U \tan ^{2} \theta+V \tan \theta+W+P / \cos ^{2} \theta\right)^{1 / 2}$ and $\gamma=X / \cos \theta+Y \tan \theta$; the $U, V$ and $W$ coefficients are mainly related to instrumental resolution, ${ }^{23} P$ and $X$ are the Scherrer coefficients for Gaussian and Lorentzian particle size broadening, respectively, and $Y$ is related to particle strain broadening. The mixing coefficient and the full width of the pseudo-Voigt function depend on $\sigma$ and $\gamma$ according to equations given in the literature. ${ }^{24}$

\section{Computational}

Quantum-mechanical calculations of the ground-state total crystal energy were performed by the computer code CRYSTAL09, ${ }^{25}$ based on the periodic LCAO (Linear Combination of Atomic Orbitals) approach. A hybrid B3LYP functional, i.e. a balanced mixture of the DFT (DensityFunctional-Theory) LYP non-local correlation ${ }^{26}$ with the DFT Becke's ${ }^{27}$ and the Hartree-Fock exchange, was employed. All-electron basis sets of Gaussian-type functions were adopted for the radial parts of atomic orbitals for $\mathrm{O}$ and $\mathrm{Li}$ atoms, according to the schemes $8(s) 411(s p) \mathrm{G}$ and $5(s) 11(s p)$, respectively. The basis set of $\mathrm{Nb}$ was based on a large core Hay-Wadt-type Effective Core Potential for inner electrons and a 31(sp)31(d)G Gaussian scheme for valence electrons.

The five tolerances related to cut-off limits for Coulomb and exchange series summation were set to $10^{-8}, 10^{-8}, 10^{-8}, 10^{-8}$, and $10^{-16}$, and DFT functionals were integrated by use of the XLGRID high accuracy conditions. The reciprocal space was sampled according to a regular sublattice of volume about $4 \times 10^{-5} \AA^{-3}$ per point, requiring a Monkhorst grid defined by 2, 10, and 2 points along the three reciprocal axes. One-electron wavefunctions were allowed to be spin-polarized, according to majority $(\alpha)$ and minority $(\beta)$ electron spins. Convergence of the SCF cycles, controlled by a $\Delta E$

threshold of $10^{-8}$ hartree per primitive unit cell, turned out to be delicate; a mixing factor of $90 \%$ with the density matrix of the previous cycle was necessary to achieve a stable iteration process. Atomic coordinates and unit-cell constants were optimized together by calculation of analytical gradients and subsequent conjugate gradients algorithm. 


\section{Results and discussion}

\section{Structural properties}

A Rietveld refinement of the crystal structure was started from the atomic coordinates of $\mathrm{Nb}$ and $\mathrm{O}$ atoms of $\alpha-\mathrm{Nb}_{2} \mathrm{O}_{5}$ in space group $P 2 / m,{ }^{15}$ with isotropic displacement factors. This structural model implies that all atoms are in special positions on mirror planes $(y$ coordinates either 0 or $1 / 2)$, except for the $\mathrm{Nb1}$ atom in tetrahedral coordination which is disordered with occupancy 0.5. After reaching convergence a difference Fourier map was computed, revealing the positions of 12 negative peaks in the asymmetric unit in special positions on mirror planes. These could be interpreted as $\mathrm{Li}$ atoms on the basis of their distances to first neighbours, and their coordinates were included in the refinement successfully. Restraints on the $\mathrm{Nb}-\mathrm{O}$ and $\mathrm{Li}-\mathrm{O}$ distances had to be introduced, in order to prevent some of these bonds to become too short. A subsequent difference Fourier map did not show any negative peaks with crystal-chemical surroundings suitable for additional $\mathrm{Li}$ atoms. Therefore, the $\mathrm{Li}_{1.714} \mathrm{Nb}_{2} \mathrm{O}_{5}$ chemical composition consistent with $24 \mathrm{Li}$ atoms per unit-cell (with 14 formula units) was accepted.

At this stage we decided to test the lower symmetry $P 2$ space group, in order to remove the severe geometric constraint of mirror symmetry on the Li atoms, which may prevent them from attaining the most favourable bonding environment. The origin on the twofold polar axis was fixed at $y(\mathrm{Nb} 2)=0$, and the $\mathrm{Nb} 1$ atom became ordered with full occupancy. Improved refinement results were obtained with respect to $P 2 / m$ symmetry, and eventually convergence was attained with the agreement factors and unit-cell constants given in Table 1. Another attempt to find additional $\mathrm{Li}$ atoms in a difference Fourier map failed. Observed, calculated and difference intensity profiles obtained after the final cycle are shown in Fig. 1. The list of refined atomic fractional coordinates and displacement factors is reported in Table 2.

One can see by the agreement factors in Table 1 and by Fig. 1 that the fit of data is quite good; however, the e.s.d.'s of atomic coordinates are larger than desirable, particularly for the $y$ values. This is yet not unexpected, despite the high quality of the experimental measurements and equipment, taking into account the large number of refined parameters due to the structure complexity (number of observations to number of variables ratio as low as 13.5). The particularly large e.s.d.'s of the $y$ coordinates are related to the strong $P 2 / m$ pseudo-symmetry of the structure, which introduces significant atomic positional correlations along [010] normal to the pseudo-plane. Other features of the results which are not fully satisfactory concern some of the displacement 
factors. Those of $\mathrm{Nb1}$ and $\mathrm{Nb} 4$ had to be fixed at quite large values; as Nb1 lies on the twofold symmetry axis, its large apparent thermal motion suggests that the symmetry should be possibly lowered to $P 1$. Other values were fixed to 0.1 to prevent them from becoming negative.

On comparing the unit-cell geometry of lithiated to unlithiated niobium oxide (Table 1), a significant volume expansion $(+5.3 \%)$ is observed, as expected. However, the effect is highly anisotropic, as all the expansion is concentrated along the [010] direction $(+8.1 \%)$, whereas the $a$ and $c$ cell edges even contract by -1.7 and $-1.2 \%$, respectively, on lithium insertion. This is related to the peculiar alignment of $\mathrm{Li}$ atoms parallel to the $\mathbf{b}$ vector, as explained below.

Indeed, the most interesting feature of the refined crystal structure of $\mathrm{Li}_{1.714} \mathrm{Nb}_{2} \mathrm{O}_{5}$ is the distribution of $\mathrm{Li}$ atoms in the framework of niobium oxide (Fig. 2). In perovskite-related structures, the preferred lithium sites are known to lie close to the square windows delimiting the cube-octahedral cages typical of these arrangements. In such cases, Li lies close to the window centre with a flat square pyramidal coordination: cf. the example of lithium-lanthanum-titanate (LLTO). ${ }^{15}$ However, $\mathrm{Nb}_{2} \mathrm{O}_{5}$ phases show an additional feature not present in the perovskite-type, but rather in the rutile-type arrangement, i.e. double planes parallel to [010] of $\mathrm{NbO}_{6}$ octahedra sharing edges (Fig. 2). Thus, Li atoms near windows in such planes acquire an extra contact with an $\mathrm{O}$ atom belonging to the neighbouring plane, so as to raise their C.N. from 4 to 5 (Fig. 3). In the structure of lithiated $\mathrm{Nb}_{2} \mathrm{O}_{5}$ there are, therefore, two kinds of possible Li sites: the tetracoordinated perovskite-type ones, and those which are pentacoordinated. These sites can be counted: there are 16 of the first and 11 of the second type per asymmetric unit.

In the structure of $\mathrm{Li}_{1.714} \mathrm{Nb}_{2} \mathrm{O}_{5}$ there are $6 \mathrm{Li}$ atoms with $\mathrm{C} . \mathrm{N} .=5$ and 6 with C.N. $=4$; they are denoted by circles and squares, respectively, in Fig. 2. The higher ratio of the number of fivefold- to fourfold-coordinated $\mathrm{Li}$ atoms (1:1) with respect to the average value $(1: 1.5)$ is consistent with the lower energy of the former class of $\mathrm{Li}$ sites, as suggested by obvious bonding considerations. However, entropic factors and non-equilibrium kinetic conditions of the lithiation reaction can also account for the significant observed fraction of $\mathrm{Li}$ atoms with C.N. $=4$.

The statistical distribution of Li-O bond distances (Fig. 4) appears to be quite asymmetric, with a fall above the most populated range (2.1 to $2.2 \AA$ ). Shorter bonds are more populated than longer bonds, so as to depress the mean value (2.064 $\AA$ ) below that range. This feature is common to both fourfold and fivefold coordinated Li atoms, whose partial distributions are not very dissimilar from the overall one. A comparable situation is observed also for the distribution of $\mathrm{Nb}-\mathrm{O}$ bond lengths, which is plotted in Fig. 5 with exclusion of the shorter bonds of tetrahedrally coordinated Nb1 (1.81 $\AA \mathrm{x} 2$ and $1.84 \AA \mathrm{x} 2)$. Again the observed mean and median (2.056 $⿱$ ) is smaller than the abscissa of the maximum $(2.15 \AA)$, giving rise to a skewed distribution. 


\section{First-principles simulations}

Starting from the experimental $P 2$ crystal structure of $\mathrm{Li}_{1.714} \mathrm{Nb}_{2} \mathrm{O}_{5}$, both atomic coordinates and unit-cell geometry were relaxed searching for least energy. The same procedure was applied to monoclinic $\alpha-\mathrm{Nb}_{2} \mathrm{O}_{5}$ as well, using again the $P 2$ space group with ordered $\mathrm{Nb} 1$ atom instead of the experimental $P 2 / m$ with split $\mathrm{Nb} 1$. The optimized unit-cell parameters of both phases are reported in Table 1, and the corresponding fractional coordinates can be obtained on request from the corresponding author. Theoretical lattice constants are moderately overestimated with respect to experimental values, as expected from the well known behaviour of the B3LYP functional. The Li$\mathrm{O}$ and $\mathrm{Nb}-\mathrm{O}$ bond length distributions were calculated and plotted in Figs. 4 and 5, below the corresponding results from neutron diffraction measurements.

In the $\mathrm{Li}-\mathrm{O}$ case, the predicted mean bond distance is slightly smaller than the experimental one (2.024 against $2.064 \AA$ ), at variance with what would be expected on the basis of the theoretical overestimate of the unit-cell constants. Further, the calculated Li-O distribution is more peaked than that from neutron diffraction, with a smaller range and a smaller variance; yet a similar asymmetry is shown in both cases. It can thus be inferred that the B3LYP functional slightly overemphasizes the strength of the ionic interaction of $\mathrm{Li}$ with the $\mathrm{O}$ nearest neighbours. On the other hand, the expected behaviour is observed for $\mathrm{Nb}-\mathrm{O}$ distances, with a theoretical mean value a bit larger than the experimental one (2.087 vs. $2.056 \AA)$. Accordingly, the distribution range is shifted to longer values, but the asymmetry is reversed.

The total energies calculated for the optimized structures of $\mathrm{Li}_{1.714} \mathrm{Nb}_{2} \mathrm{O}_{5}$ and $\alpha-\mathrm{Nb}_{2} \mathrm{O}_{5}(\mathrm{Table}$ 1) were used, together with the value (-7.528014 hartree) obtained for BCC metal lithium, to compute the electrochemical potential of the $\mathrm{Li}$ insertion reaction $(1 / \mathrm{x}) \mathrm{Nb}_{2} \mathrm{O}_{5}+\mathrm{Li} \rightarrow$ $(1 / x) \mathrm{Li}_{\mathrm{x}} \mathrm{Nb}_{2} \mathrm{O}_{5}$ (with $\mathrm{x}=12 / 7$ ). On changing the energy units into $\mathrm{eV}$, one obtains the value $-(1 / \mathrm{x})\left[\mathrm{E}\left(\mathrm{Li}_{\mathrm{x}} \mathrm{Nb}_{2} \mathrm{O}_{5}\right)-\mathrm{E}\left(\mathrm{Nb}_{2} \mathrm{O}_{5}\right)\right]+\mathrm{E}(\mathrm{Li})=1.667 \mathrm{~V}$. This is our predicted discharge voltage for the monoclinic niobium oxide cathode against a Li anode, which compares remarkably well with the experimental plateau at about $1.6 \mathrm{~V} \cdot{ }^{10,11}$

The wave functions of the least-energy structures of $\mathrm{Li}_{1.714} \mathrm{Nb}_{2} \mathrm{O}_{5}$ and $\alpha-\mathrm{Nb}_{2} \mathrm{O}_{5}$ can now be analyzed and compared, to derive the electronic and magnetic properties ensuing from the lithiation reaction. For this purpose, the well known performance of the B3LYP hybrid functional in reproducing experimental band gaps reliably will be very useful. ${ }^{16}$ At variance with the insulating character of the pure oxide, the lithiated material is predicted to be an electronic conductor with 
semi-metallic character (low density of states at the Fermi energy) and weak ferromagnetic behaviour, with a spin magnetic dipole moment of $0.55 \mu_{\mathrm{B}} /$ f.u.

The electron density of states (DOS) is shown in Fig. 6 for both unlithiated (top) and lithiated (bottom) oxides, in the energy range comprising valence band and a part of the conduction band. In addition to the total DOS (full line), also the contribution projected onto $\mathrm{Nb}$ atoms is

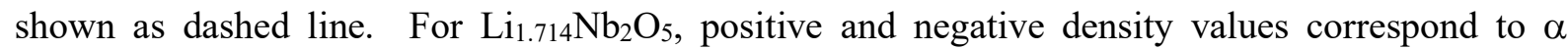
(majority spin) and $\beta$ (minority spin) polarized electrons, respectively; the energy zero was set at the Fermi energy value. The conduction bands of both phases are contributed by nearly pure $\mathrm{Nb} d$ states, whereas the valence bands are made of a main portion with prevailing $\mathrm{O}$ character, with some contribution from $\mathrm{Nb}-\mathrm{O}$ hybridization.

However, the crucial role is played by the small peak at the bottom of the conduction band of $\mathrm{Nb}_{2} \mathrm{O}_{5}$ : on lithium insertion and addition of extra electrons the Fermi energy moves upwards beyond that peak, which becomes a tiny occupied band, with a surprisingly modest relaxation of the density of states. The small band, magnified in Fig. 7, proves to have a pure $\mathrm{Nb}$ character and to be completely spin-polarized; further, it is connected to the main part of the valence band at lower energy, and to the conduction band at higher energy, by thin low-density regions which close the $3.2 \mathrm{eV}$ gap of $\mathrm{Nb}_{2} \mathrm{O}_{5}$ and explain the semi-metallic nature of $\mathrm{Li}_{1.714} \mathrm{Nb}_{2} \mathrm{O}_{5}$. A finer analysis of the DOS projections of the small band onto single $\mathrm{Nb}$ atoms shows that only four of them, $\mathrm{Nb} 4, \mathrm{Nb} 5$, $\mathrm{Nb} 11$ and $\mathrm{Nb} 15$ contribute substantially to it with their $d$-type levels. This point can be better understood by analyzing the atomic spin density distribution.

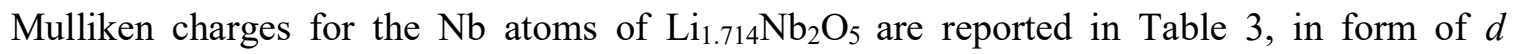
contributions for total values (sum of charges from electrons with majority $\alpha$ and minority $\beta$ spins), and of overall contributions for spin polarization density (difference of $\alpha-\beta$ charges). In facts, the $\mathrm{Nb}$ spin density is nearly completely due to contribution from $d$ electrons. As the partitioning of Mulliken electron charge between $\mathrm{Nb}$ and $\mathrm{O}$ atoms suffers of some arbitrariness, the relative rather than absolute $\alpha+\beta$ values in Table 3 are fully physically reliable. Absolute $\alpha-\beta$ spin densities, on the other hand, are free from any bias. The maximum change of $\mathrm{Nb}$ total charge is $0.6 \mathrm{e}$, indicating a not negligible tendency to charge ordering in favour of $\mathrm{Nb} 12, \mathrm{Nb} 8$ and $\mathrm{Nb} 6$ as more reduced metal atoms. Such atoms with their centrosymmetrical ones form the most condensed block of six octahedra sharing three $(\mathrm{Nb} 6)$ or four $(\mathrm{Nb} 8, \mathrm{Nb} 12)$ edges with one another and with those translated by $\pm \mathbf{b}$ (rectangular encirclement in Fig. 2). The octahedra of all other $\mathrm{Nb}$ atoms share either two or no edges with their neighbouring ones. $\mathrm{As} \mathrm{Nb}-\mathrm{Nb}$ distances become shorter with increasing 
condensation of octahedra, extra electrons can be better delocalized in the area between adjacent metal atoms at octahedra centres.

Charges on $\mathrm{Li}$ atoms range from 0.93 to $0.95 \mathrm{e}$, indicating a practically full ionization to the $\mathrm{Li}^{+}$ state. This confirms that all of lithium valence electrons move to either d-type $\mathrm{Nb}$ bands or $\mathrm{Nb}-\mathrm{O}$ hybridized levels, with no Li-O delocalized bonding contribution. On the other hand, negative charges on $\mathrm{O}$ atoms show significant variations in the -0.89 to -1.53 e range, with the expected trend of larger charges (in absolute value) for larger numbers of coordinated $\mathrm{Nb}$ and $\mathrm{Li}$ atoms.

A clear, strong ordering of the spin density on the $\mathrm{Nb} 4, \mathrm{Nb} 5, \mathrm{Nb} 11, \mathrm{Nb} 15$ atoms appears from Table 3. These atoms (included in the zigzag encirclement in Fig. 2) are exactly those contributing to the spin-polarized band shown in Fig. 7, as discussed above, and their total spin density (7.97 e/unit-cell) is similar to the overall value of 7.71 e/unit-cell. We can summarize our results by stating that, out of the 24 electrons/unit-cell added to niobium oxide by lithiation to form $\mathrm{Li}_{1.714} \mathrm{Nb}_{2} \mathrm{O}_{5}$, about one third polarize their spins concentrating in the $d$ levels of eight $\mathrm{Nb}$ atoms and giving the material a weak ferromagnetic behaviour. The rest distribute equally between $\alpha$ and $\beta$ spins, and fill valence states with hybridized $\mathrm{Nb}-\mathrm{O}$ character preferentially in the condensed blocks of six $\mathrm{NbO}_{6}$ octahedra.

Further insight into the electronic character of $\mathrm{Li}_{1.714} \mathrm{Nb}_{2} \mathrm{O}_{5}$ can be obtained by analyzing the dispersion in reciprocal space of the energy band structure. This was computed for the optimized least-energy configuration as in the DOS and Mulliken charge cases. In Fig. 8 the first Brillouin zone of the monoclinic primitive lattice is shown, and results of computations along the $\Gamma-B-D-Z$ pathway in the energy range close to Fermi energy are plotted in Fig. 9. These three sections actually represent the behaviour along all edges of the irreducible part of the B.Z., as the plots along $\Gamma-\mathrm{Y}, \mathrm{Y}-\mathrm{A}$ and $\mathrm{Y}-\mathrm{B}$ are very similar to the $\Gamma-\mathrm{B}$ one, those along Z-C, C-E and E-D correspond to the Z-D one, and the B-D plot represents also those along $\Gamma-\mathrm{Z}, \mathrm{Y}-\mathrm{C}$ and $\mathrm{A}-\mathrm{E}$. One can see that bands are very flat, practically dispersionless, in the $\Gamma-\mathrm{B}$ and $\mathrm{D}-\mathrm{Z}$ ranges corresponding to the short $\mathrm{c}^{*}$ and $\mathbf{a}^{*}$ reciprocal vectors; on the other hand, the band dispersion is large along the long $\mathbf{b}^{*}$ vector $(\Gamma-\mathrm{B})$. It is now possible to interpret the DOS of Fig. 7 in more detail. The spin-polarized ( $\alpha$ electrons only) peak in the $1.5 \mathrm{eV}$ range below $\mathrm{E}_{\mathrm{F}}$ is mainly contributed by the flat $\alpha$ bands at $k_{y}=0$ and $1 / 2$ in the same energy interval; the low-density region connecting valence to conduction states, which is responsible for electronic conductivity, is due to a few strongly dispersed $\alpha$ and $\beta$ bands crossing the Fermi energy along the $k_{y}\left(\mathbf{b}^{*}\right)$ direction.

\section{Conclusions}


Chemical lithiation of monoclinic $\alpha-\mathrm{Nb}_{2} \mathrm{O}_{5}$ has been performed, so as to mimic the corresponding electrochemical reaction during discharge vs. a lithium anode, or charge vs. a high voltage cathode.

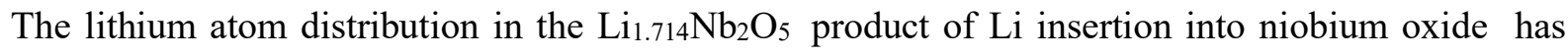
been determined by neutron diffraction. Lower energy fivefold- and a higher energy fourfoldcoordinated sites are occupied by lithium in the reaction course; the former ones are more but not exclusively populated, indicating that entropic in addition to energetic factors play a substantial role in the insertion process.

By first-principles calculations on the least-energy relaxed structure of $\mathrm{Li}_{1.714} \mathrm{Nb}_{2} \mathrm{O}_{5}$, the cathode voltage of the material vs. a $\mathrm{Li}$ anode has been computed to be $1.67 \mathrm{~V}$, in excellent agreement with the experimental plateau at $1.6 \mathrm{~V}$. This proves the ability of the B3LYP hybrid functional to predict the electrochemical potential of Li insertion electrodes correctly. Further, the effect of electrons brought by inserted Li atoms into the band structure of the solid has been demonstrated, explaining the electronic conduction properties induced in the material and predicting a weak ferromagnetism close to $0 \mathrm{~K}$. About one third of the added electrons polarize their spins and occupy a peculiar energy band just below $\mathrm{E}_{\mathrm{F}}$, which is due to pure $d$ states localized on $8 \mathrm{Nb}$ atoms out of 24 per unit-cell. The other electrons fill lower energy levels with balanced spin populations and hybridized $\mathrm{Nb}-\mathrm{O}$ character.

\section{Acknowledgements}

We thank Emmanuelle Suard (ILL, Grenoble, France) for help with the neutron diffraction data collection on the D2B equipment. 


\section{References}

1 J. Zheng, J. Xiao, X. Yu, L. Kovarik, M. Gu, F. Omenya, X. Chen, X.-Q. Yang, J. Liu, G.L. Graff, M.S. Wittingham and J.-G. Zhang, Phys. Chem. Chem. Phys., 2012, 14, 13515.

2 S.H. Kang, D.P. Abraham, W.S. Yoon, K.W. Nam and X.Q. Yang, Electrochim. Acta, 2008, 54, 684.

3 M. Anji Reddy and U.V. Varadaraju, Chem. Mater., 2008, 20, 4557.

4 J.-T. Han, D.-Q. Liu, S.-H. Song, Y. Kim and J.B. Goodenough, Chem. Mater., 2009, 21, 4753.

5 J.-T. Han and J.B. Goodenough, Chem. Mater., 2011, 23, 3404.

6 K. Nishikawa, T. Mori, T. Nishida, Y. Fukunaka and M. Rosso, J. Electroanal. Chem., 2011, 661, 84.

7 J. Yamaki, S. Tobishima, K. Hayashi, K. Saito, Y. Nemoto and M. Arakawa, J. Power Sources, 1998, 74, 219.

8 K. Nakahara, R. Nakajima, T. Matsushima and H. Majima, J. Power Sources, 2003, 117, 131.

9 L. Cheng, H.-J. Liu, J.-J. Zhang, H.-M. Xiong and Y.-Y. Xia, J. Electrochem. Soc., 2006, 153, A1472.

10 N. Kumagai, Y. Koishikawa, S. Komaba and N. Koshiba, J. Electrochem. Soc., 1999, 146, 3203.

11 R. Kodama, Y. Terada, I. Nakai, S. Komaba and N. Kumagai, J. Electrochem. Soc., 2006, 153, A583.

12 M. Wei, K. Wei, M. Ichihara and H. Zhou, Electrochem. Comm., 2008, 10, 980.

13 L.A. Reznichenko, V.V. Akhnazarova, L.A. Shilkina, O.N. Razumovskaya and S.I. Dudkina, Crystallogr. Rep., 2009, 54, 483.

14 C. Nico, M.R.N. Soares, J. Rodrigues, M. Matos, R. Monteiro, M.P.F. Graça, M.A. Valente, F.M. Costa and T. Monteiro, J. Phys. Chem. C, 2011, 115, 4879.

15 K. Kato, Acta Crystallogr. B, 1976, 32, 764.

16 J. Muscat, A. Wander and N.M. Harrison, Chem. Phys. Lett., 2001, 342, 397.

17 M. Catti and M. Montero-Campillo, J. Power Sources, 2011, 196, 3955.

18 M. Catti, Solid State Ionics, 2011, 183, 1.

19 M.D. Johannes, A.M. Stux and K.E. Swider-Lyons, Phys. Rev. B, 2008, 77, 075124.

20 F.R. Sensato, L. Gracia, A. Beltrán, J. Andrés and E. Longo, J. Phys. Chem. C, 2012, 116, 16127.

21 R.J. Cava, D.W. Murphy and S.M. Zahurak, J. Electrochem. Soc., 1983, 130, 2345. 
22 A.C. Larson and R.B. Von Dreele, General Structure Analysis System (GSAS), Los Alamos National Laboratory Report LAUR 86-748 (2004).

23 R.B. Von Dreele, J.D Jorgensen and C.G. Windsor, J. Appl. Crystallogr., 1982, 15, 581.

24 P. Thompson, D.E. Cox and J.B. Hastings, J. Appl. Crystallogr., 1987, $20,79$.

25 R. Dovesi, V. R. Saunders, C. Roetti, R. Orlando, C. M. Zicovich-Wilson, F. Pascale, B. Civalleri, K. Doll, N. M. Harrison, I. J. Bush, Ph. D’Arco, M. Llunell, CRYSTAL09 User's Manual, University of Torino, Torino, 2009.

26 C. Lee, W. Yang and R. J. Parr, Phys. Rev. B, 1998, 37, 785.

27 A. D. Becke, J. Chem. Phys., 1993, 98, 5648. 
Table 1 Rietveld refinement results of neutron diffraction data for $\mathrm{Li}_{1.714} \mathrm{Nb}_{2} \mathrm{O}_{5}$ (space group $P$, $Z=14$ ); the e.s.d.'s are reported in parentheses. Least-energy unit-cells and total energies from DFT calculations for $\mathrm{Li}_{1.714} \mathrm{Nb}_{2} \mathrm{O}_{5}$ and monoclinic $\mathrm{Nb}_{2} \mathrm{O}_{5}$.

\begin{tabular}{lrrrr}
\hline & \multicolumn{2}{c}{$\mathrm{Li}_{1.714 \mathrm{Nb}_{2} \mathrm{O}_{5}}$} & \multicolumn{2}{c}{$\alpha-\mathrm{Nb}_{2} \mathrm{O}_{5}$} \\
\hline$a(\AA)$ & Experimental & \multicolumn{1}{c}{ Theoretical } & Experimental ${ }^{15}$ & Theoretical \\
$b(\AA)$ & $20.7914(9)$ & $21.526(+3.5 \%)$ & $21.153(7)$ & $21.634(+2.3 \%)$ \\
$c(\AA)$ & $4.1346(2)$ & $4.149(+0.3 \%)$ & $3.8233(5)$ & $3.869(+1.2 \%)$ \\
$\beta\left(^{\circ}\right)$ & $19.1318(9)$ & $19.469(+1.8 \%)$ & $19.356(5)$ & $19.710(+1.8 \%)$ \\
$V\left(\AA^{3}\right)$ & $119.571(3)$ & 119.59 & $119.80(2)$ & 119.80 \\
$E($ hartree/f.u. $)$ & 1430.42 & $1512.03(+5.7 \%)$ & 1358.30 & $1431.61(+5.4 \%)$ \\
Data & 2969 & -501.89101 & & -488.88085 \\
Variables & 220 & & & \\
$w R_{p}$ & 0.0447 & & & \\
$R_{p}$ & 0.0347 & & & \\
$R\left(F^{2}\right)$ & 0.0285 & & & \\
Red. $\chi 2$ & 3.922 & & & \\
& & & & \\
\hline
\end{tabular}


Table 2 Refined atomic fractional coordinates and displacement factors of $\mathrm{Li}_{1.714} \mathrm{Nb}_{2} \mathrm{O}_{5}$, with e.s.d.'s in parentheses.

\begin{tabular}{|c|c|c|c|c|}
\hline & $x$ & $y$ & $z$ & $U\left(10^{2} \AA^{2}\right)$ \\
\hline $\mathrm{Nb} 1$ & 0 & $0.265(30)$ & 0 & 80 \\
\hline $\mathrm{Nb} 2$ & 0.5 & 0.0000 & 0.5 & $0(1)$ \\
\hline $\mathrm{Nb3}$ & $0.1506(31)$ & $0.008(26)$ & $0.9765(34)$ & $8(2)$ \\
\hline $\mathrm{Nb} 4$ & $0.240(4)$ & $0.950(27)$ & $0.237(4)$ & 40 \\
\hline $\mathrm{Nb} 5$ & $0.2956(22)$ & $0.014(20)$ & $0.4574(22)$ & $1(1)$ \\
\hline $\mathrm{Nb6}$ & $0.3569(34)$ & $0.973(26)$ & $0.026(4)$ & $14(4)$ \\
\hline $\mathrm{Nb} 7$ & $0.4217(28)$ & $0.955(19)$ & $0.2498(28)$ & $5(2)$ \\
\hline $\mathrm{Nb} 8$ & $0.5738(16)$ & $0.983(19)$ & $0.0717(17)$ & 0.1 \\
\hline $\mathrm{Nb9}$ & $0.6349(17)$ & $0.977(19)$ & $0.3152(18)$ & 0.1 \\
\hline $\mathrm{Nb} 10$ & $0.1044(18)$ & $0.471(19)$ & $0.1978(20)$ & 0.1 \\
\hline $\mathrm{Nb} 11$ & $0.167(4)$ & $0.491(30)$ & $0.427(4)$ & $18(4)$ \\
\hline $\mathrm{Nb} 12$ & $0.6829(17)$ & $0.474(18)$ & $0.0981(18)$ & 0.1 \\
\hline $\mathrm{Nb} 13$ & $0.7574(19)$ & $0.448(18)$ & $0.3383(20)$ & 0.1 \\
\hline $\mathrm{Nb} 14$ & $0.8927(24)$ & $0.491(18)$ & $0.1446(26)$ & $3(1)$ \\
\hline $\mathrm{Nb} 15$ & $0.9655(22)$ & $0.435(17)$ & $0.3888(21)$ & $2(1)$ \\
\hline $\mathrm{O} 1$ & 0 & $0.456(35)$ & 0.5 & $5(3)$ \\
\hline $\mathrm{O} 2$ & 0.5 & $0.560(15)$ & 0.5 & 0.1 \\
\hline $\mathrm{O} 3$ & $0.1237(27)$ & $0.978(23)$ & $0.209(4)$ & $12(4)$ \\
\hline $\mathrm{O} 4$ & $0.1807(29)$ & $0.011(24)$ & $0.4323(30)$ & $3(2)$ \\
\hline O5 & $0.1902(23)$ & $0.929(16)$ & $0.1104(25)$ & 0.1 \\
\hline O6 & $0.2600(18)$ & $0.987(17)$ & $0.3353(19)$ & 0.1 \\
\hline $\mathrm{O} 7$ & $0.2521(18)$ & $0.951(19)$ & $0.0057(20)$ & 0.1 \\
\hline O8 & $0.3210(23)$ & $0.041(18)$ & $0.2366(26)$ & $2(1)$ \\
\hline O9 & $0.4006(26)$ & $0.116(19)$ & $0.4796(32)$ & $4(2)$ \\
\hline $\mathrm{O} 10$ & $0.3922(20)$ & $0.025(18)$ & $0.1462(21)$ & 0.1 \\
\hline O11 & $0.472(4)$ & $0.989(25)$ & $0.3828(31)$ & $11(3)$ \\
\hline $\mathrm{O} 12$ & $0.4628(30)$ & $0.072(23)$ & $0.049(4)$ & $11(4)$ \\
\hline $\mathrm{O} 13$ & $0.5292(17)$ & $0.047(17)$ & $0.2742(22)$ & 0.1 \\
\hline $\mathrm{O} 14$ & $0.6106(27)$ & $0.031(21)$ & $0.1905(25)$ & $2(1)$ \\
\hline $\mathrm{O} 15$ & $0.6632(19)$ & $0.006(18)$ & $0.4278(20)$ & 0.1 \\
\hline O16 & $0.6870(28)$ & $0.987(21)$ & $0.1041(29)$ & $3(1)$ \\
\hline O17 & $0.7575(19)$ & $0.011(18)$ & $0.3455(23)$ & 0.1 \\
\hline $\mathrm{O} 18$ & $0.895(4)$ & $0.999(19)$ & $0.1574(30)$ & $8(3)$ \\
\hline O19 & $0.9572(19)$ & $0.009(18)$ & $0.0425(22)$ & 0.1 \\
\hline $\mathrm{O} 20$ & $0.9514(32)$ & $0.957(18)$ & $0.3693(29)$ & $6(2)$ \\
\hline $\mathrm{O} 21$ & $0.0715(18)$ & $0.510(19)$ & $0.0816(18)$ & $12(4)$ \\
\hline $\mathrm{O} 22$ & $0.0695(18)$ & $0.480(20)$ & $0.4046(20)$ & 0.1 \\
\hline $\mathrm{O} 23$ & $0.1371(19)$ & $0.506(19)$ & $0.3143(20)$ & 0.1 \\
\hline $\mathrm{O} 24$ & $0.2176(21)$ & $0.450(17)$ & $0.2266(22)$ & 0.1 \\
\hline $\mathrm{O} 25$ & $0.2829(21)$ & $0.526(17)$ & $0.4553(19)$ & 0.1 \\
\hline
\end{tabular}




\begin{tabular}{llllc} 
O26 & $0.3493(21)$ & $0.502(19)$ & $0.0145(25)$ & $1(1)$ \\
O27 & $0.4267(26)$ & $0.472(17)$ & $0.260(4)$ & $4(2)$ \\
O28 & $0.5712(20)$ & $0.492(19)$ & $0.0725(22)$ & 0.1 \\
O29 & $0.6421(24)$ & $0.469(19)$ & $0.3207(27)$ & $3(2)$ \\
O30 & $0.7129(21)$ & $0.505(20)$ & $0.2274(21)$ & 0.1 \\
O31 & $0.7774(29)$ & $0.462(22)$ & $0.4508(26)$ & $10(3)$ \\
O32 & $0.8009(21)$ & $0.494(20)$ & $0.1362(26)$ & $2(1)$ \\
O33 & $0.8535(23)$ & $0.520(19)$ & $0.3525(28)$ & $2(1)$ \\
O34 & $0.8484(21)$ & $0.481(20)$ & $0.0140(21)$ & 0.1 \\
O35 & $0.9347(17)$ & $0.453(17)$ & $0.2721(18)$ & 0.1 \\
O36 & $0.990(4)$ & $0.531(26)$ & $0.172(4)$ & $14(5)$ \\
Li1 & $0.371(4)$ & $0.01(4)$ & $0.353(4)$ & 0.1 \\
Li2 & $0.754(4)$ & $0.970(27)$ & $0.445(4)$ & 0.1 \\
Li3 & $0.866(4)$ & $0.040(23)$ & $0.406(5)$ & 0.1 \\
Li4 & $0.294(4)$ & $0.136(29)$ & $0.125(5)$ & 0.1 \\
Li5 & $0.726(6)$ & $0.008(29)$ & $0.233(5)$ & $7(7)$ \\
Li6 & $0.171(5)$ & $0.408(24)$ & $0.107(5)$ & 0.1 \\
Li7 & $0.966(5)$ & $0.963(25)$ & $0.280(4)$ & 0.1 \\
Li8 & $0.043(4)$ & $0.380(28)$ & $0.277(5)$ & 0.1 \\
Li9 & $0.253(4)$ & $0.483(25)$ & $0.352(4)$ & 0.1 \\
Li10 & $0.666(5)$ & $0.506(25)$ & $0.436(4)$ & 0.1 \\
Li11 & $0.515(4)$ & $0.550(23)$ & $0.278(7)$ & 0.1 \\
Li12 & $0.470(4)$ & $0.589(26)$ & $0.050(6)$ & 0.1 \\
& & & & \\
\hline & & & & \\
\hline
\end{tabular}


Table 3 Total $(\alpha+\beta) d$ shell charge and overall spin $(\alpha-\beta)$ charge (electron units) from DFT calculations for $\mathrm{Nb}$ atoms in $\mathrm{Li}_{1.714} \mathrm{Nb}_{2} \mathrm{O}_{5}$.

\begin{tabular}{lll}
\hline & total $d$ charge & spin charge \\
\hline $\mathrm{Nb} 1$ & 2.628 & \\
$\mathrm{Nb} 2$ & 2.420 & 0.012 \\
$\mathrm{Nb} 3$ & 2.727 & 0.006 \\
$\mathrm{Nb} 4$ & 2.620 & 0.000 \\
$\mathrm{Nb} 5$ & 2.614 & 0.966 \\
$\mathrm{Nb} 6$ & 2.847 & 0.925 \\
$\mathrm{Nb} 7$ & 2.435 & 0.032 \\
$\mathrm{Nb} 8$ & 3.023 & 0.064 \\
$\mathrm{Nb} 9$ & 2.650 & -0.004 \\
$\mathrm{Nb} 10$ & 2.504 & 0.071 \\
$\mathrm{Nb} 11$ & 2.590 & 0.164 \\
$\mathrm{Nb} 12$ & 3.035 & 0.921 \\
$\mathrm{Nb} 13$ & 2.718 & 0.000 \\
$\mathrm{Nb} 14$ & 2.733 & 0.091 \\
$\mathrm{Nb} 15$ & 2.502 & 0.009 \\
& & 0.739 \\
\hline
\end{tabular}


Captions of the figures

Fig. 1 Neutron powder diffraction pattern (ILL-D2B, $\lambda=1.5951 \AA$ ) of $\mathrm{Li}_{1.714} \mathrm{Nb}_{2} \mathrm{O}_{5}$; observed, Rietveld calculated and difference intensity profiles are plotted vs. the $2 \theta$ angle $\left(^{\circ}\right)$.

Fig. 2 Projection onto (010) of the $P 2$ structure of $\mathrm{Li}_{1.714} \mathrm{Nb}_{2} \mathrm{O}_{5}$, from Rietveld refinement of neutron diffraction data. $\mathrm{NbO}_{6}$ coordination octahedra are shown; circles and squares emphasize fivefold- and fourfold-coordinated Li atoms, respectively. For the two large encirclements, see the text.

Fig. 3 Crystal-chemical environment of fivefold-coordinated $\mathrm{Li}$ atoms in the structure of

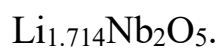

Fig. 4 Statistical distribution of the Li-O bond lengths from fivefold- and fourfold-coordinated Li atoms in the structure of $\mathrm{Li}_{1.714} \mathrm{Nb}_{2} \mathrm{O}_{5}$. Top: neutron diffraction results; bottom: DFT calculations.

Fig. 5 Statistical distribution of the $\mathrm{Nb}-\mathrm{O}$ bond lengths from $\mathrm{NbO}_{6}$ coordination octahedra in the

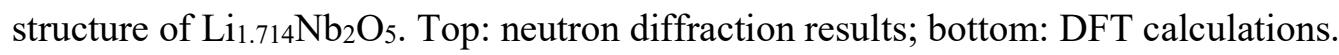

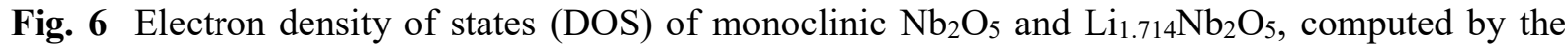
hybrid DFT-HF B3LYP functional. Full and dashed lines show the total DOS and the contribution due to $\mathrm{Nb}$ atoms, respectively. For $\mathrm{Li}_{1.714} \mathrm{Nb}_{2} \mathrm{O}_{5}$, spin majority $\alpha$ and minority $\beta$ states correspond to the positive and the negative vertical directions.

Fig. 7 Magnification of the DOS of $\mathrm{Li}_{1.714} \mathrm{Nb}_{2} \mathrm{O}_{5}$ (Fig. 6), showing the spin-polarized occupied band due to $d$ states of $\mathrm{Nb} 4, \mathrm{Nb} 5, \mathrm{Nb} 11$ and $\mathrm{Nb} 15$ atoms.

Fig. 8 Brillouin zone of the monoclinic $P$ lattice (Bilbao Crystallographic Server, http://www.cryst.ehu.es).

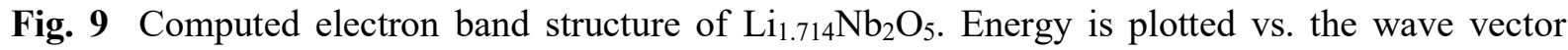
fractional coordinate $k$, along the $\Gamma(0,0,0)$ to $\mathrm{B}(0,0,1 / 2), \mathrm{D}(0,1 / 2,1 / 2)$, and $\mathrm{Z}(0,1 / 2,0)$ pathway in reciprocal space. Full and dotted lines represent energies of majority $\alpha$ and minority $\beta$ spin states, respectively. 


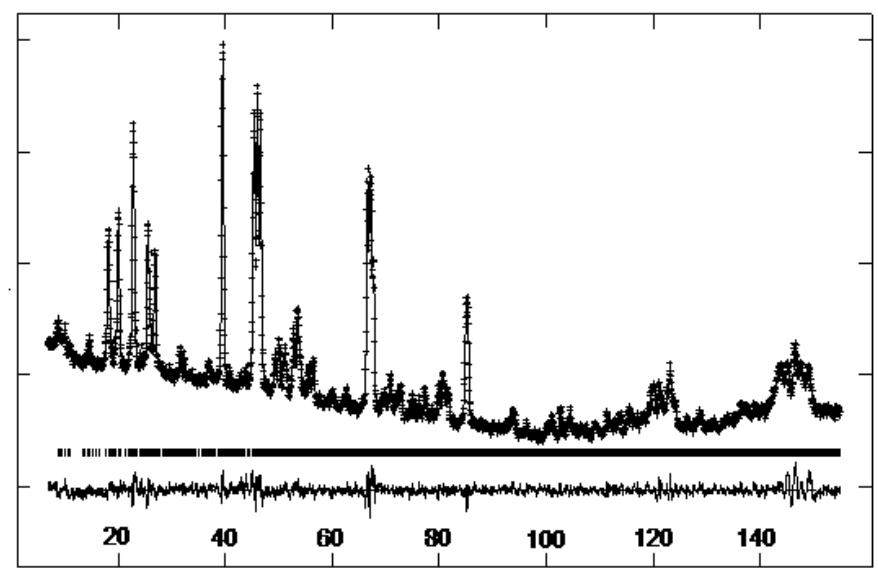

Fig. 1 


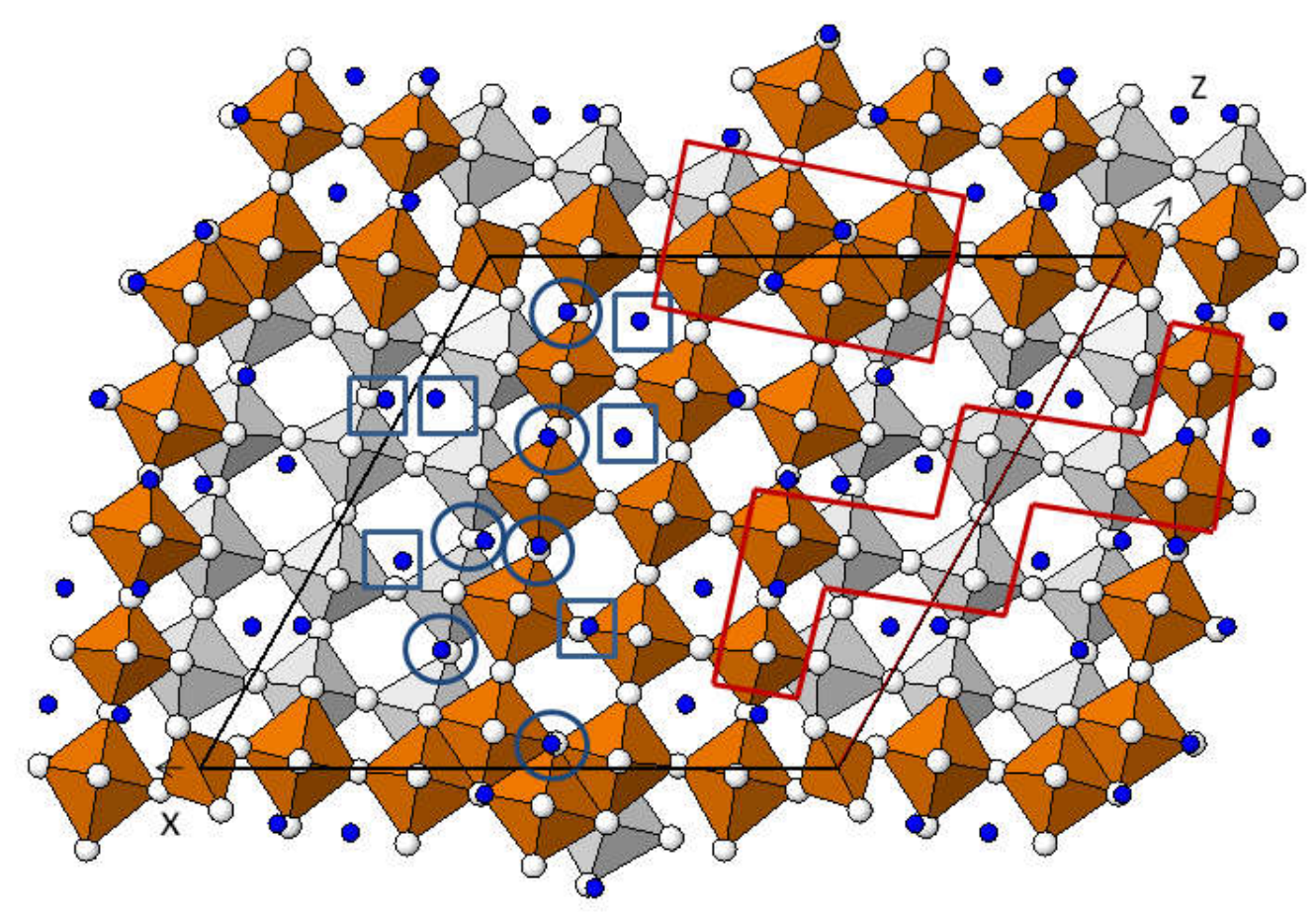

Fig. 2 


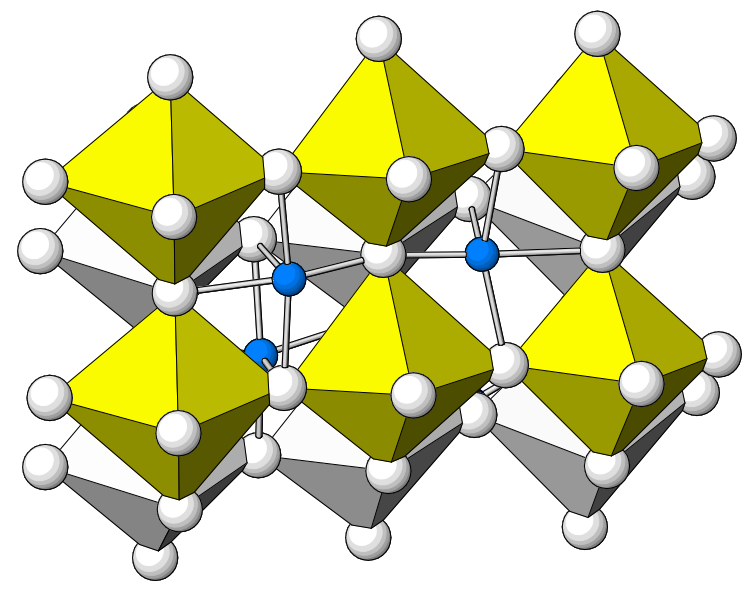

Fig. 3 


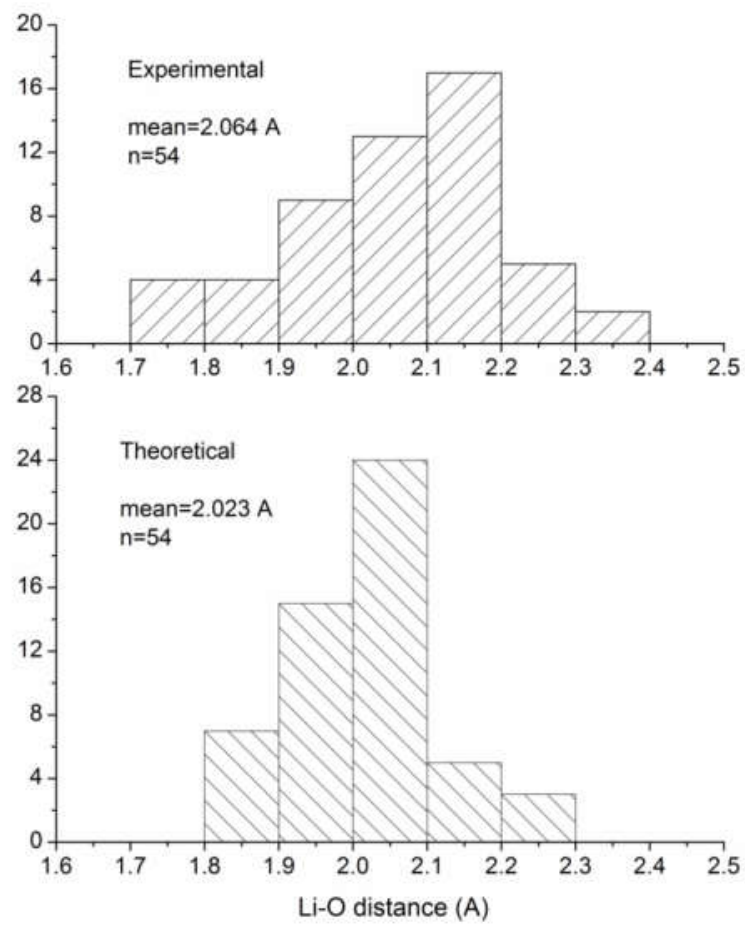

Fig. 4 

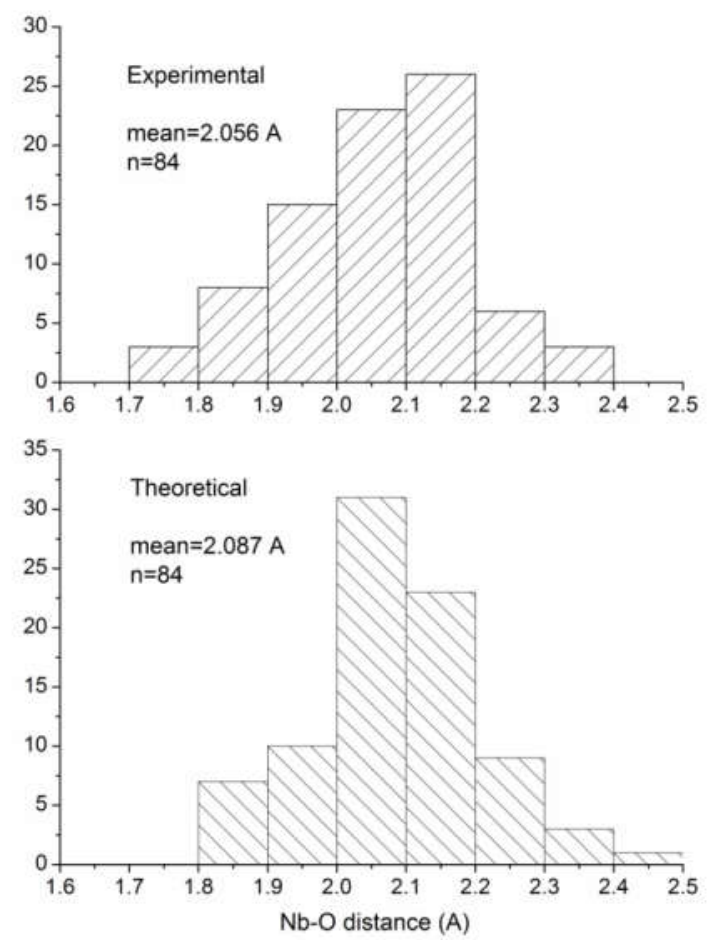

Fig. 5 


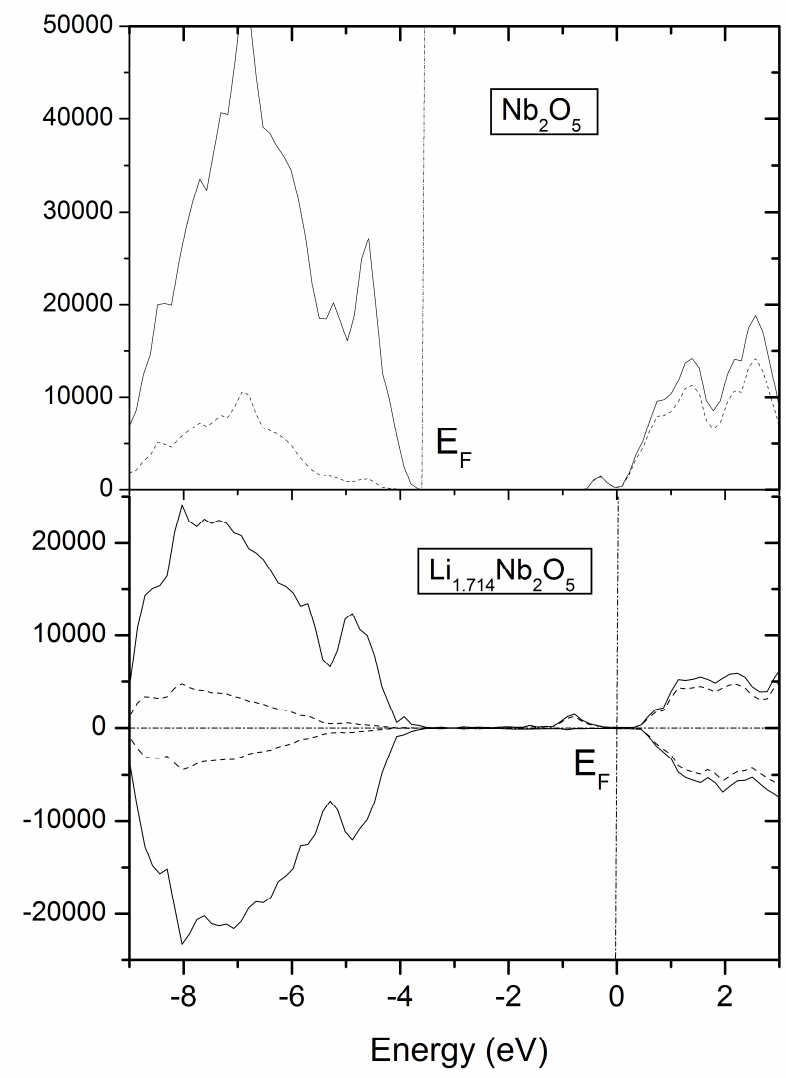

Fig. 6 


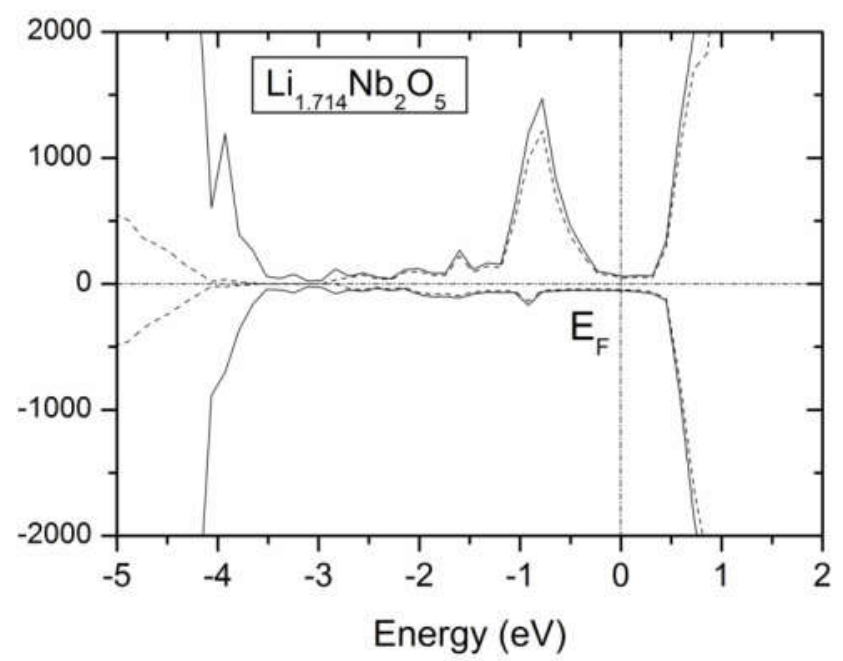

Fig.. 7 


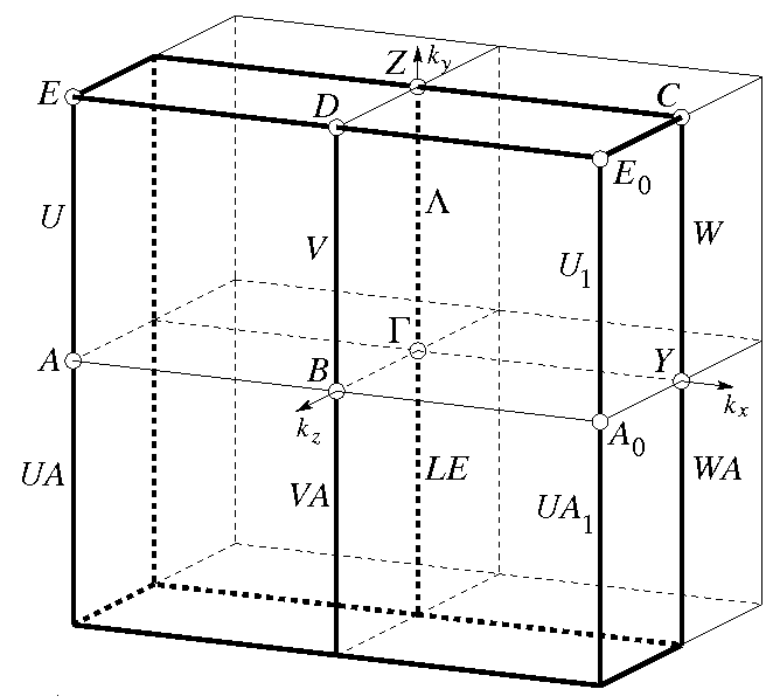

Fig. 8 


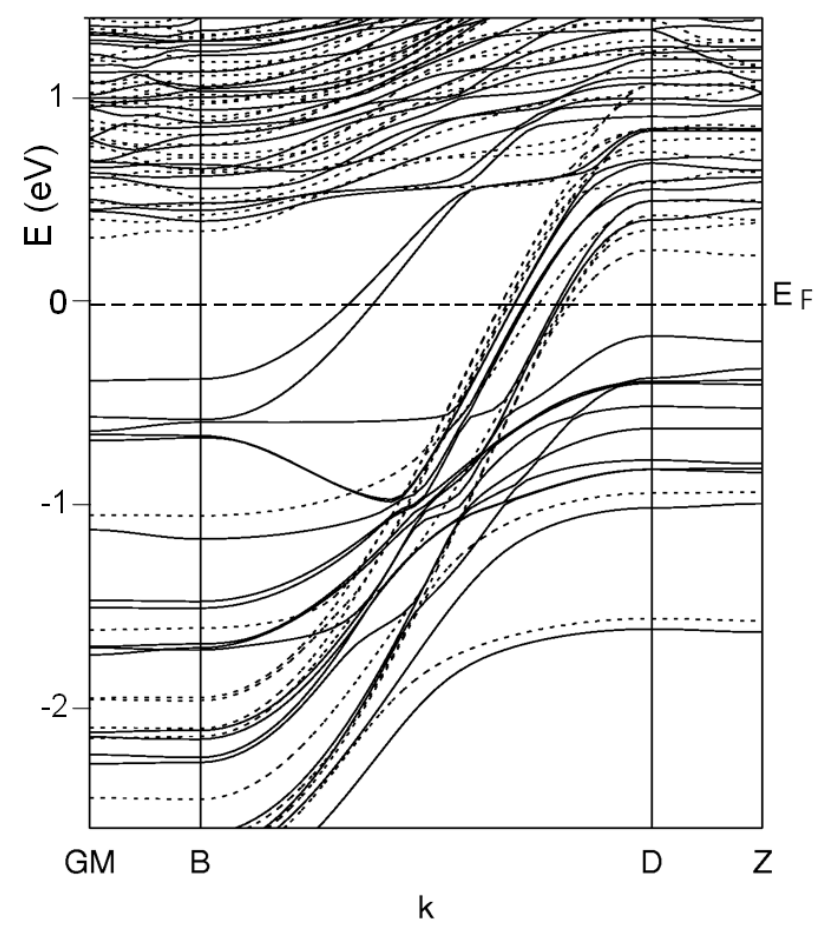

Fig. 9 